\title{
EFEITOS DA GESTÃO PARTICIPATIVA DOS PARQUES ESTADUAIS DA BAHIA
}

\author{
José Alberto Castro Macedo; José Augusto Drummond
}

\begin{abstract}
RESUMO
Neste artigo são discutidos os efeitos da participação sobre a gestão de três parques estaduais da Bahia - Serra do Conduru, Morro do Chapéu e Sete Passagens a partir da técnica "Medición de la efectividad del manejo de areas protegidas", proposta por Cifuentes, Izurieta e De Faria (2000). As fontes abrangem documentos das unidades, respostas a questionários, entrevistas com funcionários dos parques e anotações de trabalho de campo. O pressuposto é o de que o pouco envolvimento das comunidades leva a uma gestão insatisfatória. Para cada unidade foi calculado um índice de efetividade. Sete Passagens e Serra do Conduru têm a gestão mais participativa, com 71 e 57 pontos, respectivamente (numa escala de 1 a 100), alcançando gestão medianamente satisfatória. Morro do Chapéu alcançou 37, ficando na categoria de gestão pouco satisfatória. Isso indica que a qualidade da gestão se correlaciona com a gestão participativa.
\end{abstract}

Palavras-chave: Gestão participativa; unidades de conservação; parques estaduais

\section{TERRITORIAL TENSIONS AND DYNAMICS: TRADITIONAL PEOPLES AND COMMUNITIES IN THE DEVELOPMENT CONTEXT OF PERNAMBUCO}

\begin{abstract}
In this article we discuss the effects of participation on the management of three state parks in Bahia (Brazil) - Serra do Conduru, Morro do Chapéu and Sete Passagens, using the technique called "Measurement of the effectiveness of protected area management", proposed by Cifuentes, Izurieta and De Faria (2000). Data came from parks' documents, answers to questionnaires, interviews with Park's Staff and field observations. The hypothesis is that weak community involvement leads to poor management. An effectiveness index was calculated for each park. Sete Passagens and Serra do Conduru scored highest for participatory management, with 71 and 57 points, respectively (on a scale of 1 to 100), meaning a moderately satisfactory management. Morro do Chapéu scored only 37 points, meaning moderately unsatisfactory management. These results indicate that management quality correlates with participatory management.
\end{abstract}

Key words: Participatory Management; Conservation Unities; State Parks

José Alberto Castro Macedo. M. Sc., Desenvolvimento Sustentável, Universidade de Brasília. E-mail:josealberto.macedo@gmail.com; josealberto.macedo@ sema.ba.gov.br. José Augusto Drummond. Ph. D., Land Resources, University of Wisconsin, Madison (EUA), professor associado III, Centro de Desenvolvimento Sustentável, Universidade de Brasília. E-mail: jaldrummond@uol.com.br 


\section{INTRODUÇÃO}

Este artigo discute os processos de governança de três unidades de conservação (UCs) de proteção integral, criadas pelo estado da Bahia - os parques estaduais Serra do Conduru, Morro do Chapéu e Sete Passagens. Visa descrever e avaliar o estágio atual dessas UCs no que diz respeito a questões ambientais, político-institucionais, administrativas e fundiárias e às relações com as populações locais. Atenção especial é dada à participação social, a mecanismos que permitam a igualdade de acesso aos benefícios gerados e à eficiência na conservação dos recursos naturais e da qualidade ambiental. Parte-se do pressuposto de que esses componentes culminariam numa gestão ambiental mais participativa, ampliando o sentido de governo local para o de uma governança local.

Para Leite (2004), a elaboração de legislação ambiental, a normatização do uso da terra e a criação de UCs são medidas significativas adotadas pela maioria das nações para proteger e conservar os recursos naturais ${ }^{1}$ Examinamos as diretrizes teóricas da gestão das UCs, no que concerne à gestão participativa e aos processos de governança, para entender como ocorre a gestão dos três únicos parques estaduais baianos.

Adotamos a premissa de que o pouco envolvimento das comunidades locais ou a opção de gestores de envolve-las pode contribuir para um desempenho pouco satisfatório da gestão das UCs, ou mesmo para agravar conflitos pré- existentes. Ou seja, a conservação da biodiversidade não é garantida apenas pela existência de UCs. As formas de se implantar e gerenciar esses espaços protegidos são fundamentais para o alcance de seus objetivos. Assim, julgamos que a adoção de métodos participativos, desde a criação até o manejo sistemático, implica ganhos substanciais na manutenção da biodiversidade e da qualidade ambiental das áreas e na minimização dos conflitos em relação ao uso e à ocupação do solo em seus entornos.

$\mathrm{O}$ uso de mecanismos de governança e de participação social nas UCs baianas ainda é pouco estudado. Este texto está embasado em dados inéditos, produzidos por meio de sondagens feitas diretamente junto a atores pertinentes. Espera-se que o conjunto original de dados levantados e a sua análise esclarecerão diversos pontos e subsidiarão pesquisadores, visitantes e as populações locais quanto aos objetivos das UCs e propiciarão um maior envolvimento de todos na salvaguarda dos atributos naturais, socioeconômicos e culturais de UCs.

Metodologicamente, o texto se baseia em um procedimento adaptado de uma técnica denominada "medición de la efectividad del manejo de areas protegidas", idealizado por Cifuentes, Izurieta e De Faria (2000). Os indicadores que eles usaram foram validados em exercícios de medição da efetividade do manejo de espaços protegidos referentes a áreas protegidas de diversos países da América Latina, inclusive o Brasil. Este procedimento flexível foi adaptado para a realidade das UCs baianas.

1. Adotamos o termo unidades de conservação conforme definido na Lei no 9.985, de 18 de julho de 2000 . Trata-se de “espaço territorial e seus recursos ambientais, incluindo as águas jurisdicionais, com características naturais relevantes, legalmente instituídas pelo Poder Público, com objetivos de conservação e limites definidos, sob regime especial de administração, ao qual se aplicam garantias adequadas de proteção”. 
Pelo menos dois trabalhos de avaliação da efetividade da gestão de UCs brasileiras adotaram esta metodologia e assim forneceram um contexto teórico e empírico para a presente investigação. O primeiro é de autoria do Instituto de Pesquisas da Mata Atlântica (IPEMA, 2003), focalizando UCs situadas no Corredor Central da Mata Atlântica. O segundo, escrito por Carvalho (2004), focalizou as áreas de proteção ambiental - APAs estaduais da Bahia.

As variáveis examinadas no presente estudo foram selecionadas entre aquelas discutidas pelas teorias de governança. Graham, Amos e Plumtre (2003) propõem cinco princípios para a avaliação da governança em UCs: legitimidade e voz; direcionamento; desempenho; prestação de contas; e equidade. Já o PNUD definiu oito princípios de boa governança de áreas protegidas: estado de direito; responsabilidade; orientação por consenso; participação de múltiplos atores; igualdade e inclusividade; transparência; abertura à auditoria; e efetividade e eficiência (DRUMMOND et alli, 2006). Esses oito critérios foram definidos a partir de consensos internacionais, expressos em declarações e princípios acordados na ONU. Para os fins da presente pesquisa, os 13 princípios mencionados foram sintetizados em cinco - legitimidade e participação de múltiplos atores; igualdade e inclusividade; responsabilidade $e$ transparência; abertura à auditoria e equidade; e efetividade e eficiência -. Essa síntese, necessária para facilitar a operacionalização da pesquisa, foi feita a partir de um processo de composição, com base em critérios de similaridade e inclusão.

Parte das informações necessárias foi colhida em documentos de diversas esferas de governo. No entanto, a maior parte dos dados veio da adoção de técnicas de observação participante e da aplicação de questionários e entrevistas, junto aos membros dos conselhos gestores dos parques estudados. Escolhemos esses atores por serem, os conselhos gestores, a principal instância de construção da governança ampliada.

Eis as perguntas que este artigo busca responder: os envolvidos têm direito a voz? Há autonomia na gestão? Existem instrumentos de gestão - plano de manejo, zoneamento, regimento interno do conselho? Qual a situação deles? A gestão é pautada em planos de longo prazo para a consolidação da governança local? Existem parcerias instituídas? Como os parceiros envolvidos na gestão coordenam a sua ação? As informações necessárias estão disponíveis? Qual é a relação entre recursos empregados e resultados obtidos? Quem presta contas de que, e a quem? Existe imparcialidade na aplicação das normas? Houve respeito aos direitos da população local no processo de criação das unidades? Foram cometidas injustiças? Quais são os principais conflitos relacionados à gestão das UCs?

Os dados usados para dar respostas a essas perguntas foram submetidos a técnicas de análise quantitativa, permitindo cruzar as informações sobre as três unidades. O modelo analítico usado é composto por seis setores temáticos (gestor do parque, financiamento, avaliação das relações sociais e políticas, avaliação do âmbito legal, avaliação do âmbito planejamento e avaliação do âmbito do conhecimento), divididos em 25 questões (variáveis e subvariáveis). Cada questão contém cinco alternativas $(0,1,2,3$ e 4), com uma pontuação máxima de 4,0 pontos, perfazendo, portanto, um total potencial máximo de 100 pontos. As 25 questões foram divididas em grupos de cinco, não necessariamente sequenciadas na 
estrutura do questionário. Cada grupo tem uma relação direta com um dos princípios da governança citados. O valor de cada variável foi obtido por meio do somatório geral das alternativas assinaladas, dividido pelo número de conselheiros entrevistados. Quando foi necessário, foram aplicadas regras matemáticas de aproximação.

A matriz de avaliação se baseia na construção de cenários de gestão para cada variável ou subvariável. A pontuação máxima (4) equivale ao "ótimo de gestão" para aquela variável ou subvariável específica. Dessa forma, o cenário ótimo ou total ótimo corresponde às melhores condições possíveis de governança ambiental. O cenário atual ou o total alcançado, por outro lado, corresponde à situação da unidade no momento da avaliação (FARIA, 2006). Dessa forma, o ótimo numérico de cada princípio é a soma da pontuação máxima alcançada pelas variáveis e subvariáveis, ou seja, 20 pontos. O valor atual de cada princípio corresponde à soma das pontuações alcançadas. Para valorar a gestão participativa, realizou-se o somatório alcançado por todas as variáveis e subvariáveis. A escala de qualificação adotada tem cinco níveis (0 a 4), associados a uma ponderação percentual que expressa o grau de gestão participativa, de insatisfatória a muito satisfatória, conforme o Quadro 1, abaixo.

Quadro 1 - Escala de qualificação e ponderação da gestão participativa dos parques estaduais da Bahia.

\begin{tabular}{|c|c|c|}
\hline qualifi-cação & \% do ótimo & \multicolumn{1}{c|}{ significado } \\
\hline 0 & $<35$ & \multicolumn{1}{c|}{ gestão insatisfatória } \\
& & $\begin{array}{l}\text { Administração altamente centralizada, sem participação de } \\
\text { atores locais, desde a criação da UC. Não existem gestor no- } \\
\text { meado ou instrumentos auxiliares (conselho gestor, planos de } \\
\text { manejo, plano anual de gestão). Limites não foram demarcados, } \\
\text { gerando conflitos fundiários. Inexistem equipamentos de apoio } \\
\text { à gestão e faltam os recursos mínimos. Não existem garantias de } \\
\text { permanência a longo prazo. Os objetivos de conservação não são } \\
\text { alcançáveis. }\end{array}$ \\
\hline \multirow{2}{*}{$36-50$} & $\begin{array}{l}\text { Há alguns recursos e meios indispensáveis, mas abaixo do nível } \\
\text { mínimo aceitável. Existe gestor nomeado, residindo no local, } \\
\text { mas ele não envolve atores locais. A área está demarcada, porém } \\
\text { os limites não são aceitos pela comunidade, gerando conflitos. } \\
\text { Não há instrumentos de gestão e o conselho gestor se reúne rara- } \\
\text { mente. A UC tem alta vulnerabilidade e durabilidade duvidosa. } \\
\text { Os objetivos de conservação dificilmente serão alcançados. }\end{array}$ \\
\hline
\end{tabular}




\begin{tabular}{|c|c|c|}
\hline 2 & $51-75$ & $\begin{array}{l}\text { gestão medianamente satisfatória } \\
\text { Há elementos mínimos de gestão participativa, contudo defi- } \\
\text { ciências minam a efetividade. Existe um gestor nomeado, resi- } \\
\text { dente no local e aceito pela comunidade. Existe um conselho } \\
\text { gestor, mas pouco frequentado. Existe uma estrutura de apoio } \\
\text { à gestão (sede e equipamentos). Existem parceiros e acordos de } \\
\text { cooperação. Há recursos financeiros mínimos. Os limites estão } \\
\text { definidos e aceitos, contudo disputas fundiárias não foram re- } \\
\text { solvidas. Existe ou está em elaboração o plano de manejo. Há } \\
\text { normas e regulamentos que não são respeitados, gerando confli- } \\
\text { tos que comprometem o alcance dos objetivos da UC. }\end{array}$ \\
\hline 3 & $76-90$ & $\begin{array}{l}\text { gestão satisfatória } \\
\text { Há fatores e meios adequados para a gestão participativa. Existe } \\
\text { um gestor que trabalha de forma participativa e compartilhada. } \\
\text { Ele conta com uma estrutura de apoio (sede e equipamentos) } \\
\text { que facilita o acesso dos atores. O conselho gestor é atuante e } \\
\text { mobilizado. Existem parcerias e cogestões e recursos financeiros } \\
\text { compatíveis. Os limites da UC estão definidos e aceitos e a situa- } \\
\text { ção fundiária está praticamente regularizada. Contudo, o plano } \\
\text { de manejo está desatualizado e algumas normas não são respeita- } \\
\text { das, gerando pequenos conflitos. As atividades se desenvolvem } \\
\text { normalmente e com bons resultados, garantido o alcance dos } \\
\text { objetivos da UC. }\end{array}$ \\
\hline 4 & $91-100$ & $\begin{array}{l}\text { gestão muito satisfatória } \\
\text { Existem diversos mecanismos de gestão participativa, descen- } \\
\text { tralizada e transversal. O gestor dispõe de uma equipe técnica } \\
\text { qualificada e de infraestrutura física e equipamentos suficientes. } \\
\text { O conselho gestor é atuante, os instrumentos de gestão estão } \\
\text { atualizados e todas as normas e regulamentos são aplicados e } \\
\text { respeitados. A situação fundiária está regularizada e os principais } \\
\text { conflitos foram mitigados. A UC conta com todos os meios para } \\
\text { uma gestão eficiente para as demandas atuais. O cumprimento } \\
\text { dos objetivos de conservação está garantido. }\end{array}$ \\
\hline
\end{tabular}

Fonte: Adaptado de CIFUENTES; IZURIETA E DE FARIA (2000). 
O modelo adotado de entrevista semiestruturado - foi concebido para subsidiar a análise qualitativa. Foi composto por 21 questões abertas e duas fechadas. A análise qualitativa foi enriquecida com os resultados obtidos por meio da observação participante.

A pesquisa constatou que existem diferenças significativas na qualidade de gestão dos três parques estaduais estudados e que essas diferenças estão correlacionadas com o grau de participação não-governamental na gestão dessas UCs.

Eis dados básicos sobre os três parques estaduais baianos estudados.

- Parque Estadual da Serra do Conduru - PESC Criado pelo Decreto Estadual $\mathrm{n}^{\circ}$ 6.227, de 21/2/1997, com 9.275 ha, situa-se nos municípios de Uruçuca (45\%), Itacaré (40\%) e Ilhéus (15\%), na região do Litoral Sul baiano. Está inserida na Área de Proteção Ambiental de Itacaré / Serra Grande. Há outras duas APAs em seu entorno, Lagoa Encantada e Península de Maraú (FLORESTAVIVA, 2007). Segundo Ângelo (2003), os seus principais aspectos ambientais são: (1) o alto índice de biodiversidade; (2) um dos mais importantes blocos de remanescentes da Mata Atlântica da costa nordestina, com elevados níveis de formas endêmicas de vida; e (3) a conservação das florestas da unidade mantém a qualidade da água fornecida por cerca de 30 nascentes. O alto potencial ecoturístico foi outro fator de criação dessa UC.

\section{- Parque Estadual do Morro do Chapéu - PEMC}

Localizado na Chapada Diamantina Setentrional, no semiárido, o parque, situado no município de mesmo nome, foi criado pelo Decreto Estadual $n^{\circ} 7.413$, de 17/8/1998, com 46.000 ha. A UC objetiva (1) preservar espé- cies vegetais em perigo de extinção; (2) manter espécies da fauna silvestre; e (3) integrar instituições municipais, estaduais e federias para execução de programas de cunho científico e educacional (UEFS, 2006).

\section{- Parque Estadual das Sete Passagens - PESP} Criado pelo Decreto Estadual $\mathrm{n}^{\circ} 7.808$, de 25/5/2000, com 2.821 ha, o parque fica no município de Miguel Calmon, no semiárido (SEMARH, 2006). A criação dessa UC se deveu às pressões exercidas por garimpos, criadores de gado e empresas de mineração. $\mathrm{O}$ motivo forte de criação da UC foi a manutenção da qualidade e quantidade dos recursos hídricos que servem comunidades do entorno. Outro motivo foi evitar que a antiga Mineradora Morro Velho, atual Jacobina Mineração S.A, que explora ouro em Jacobina, minerasse do lado de Miguel Calmon (SEAGRI, 1997). Atualmente, as comunidades locais se abastecem com água de excelente qualidade. Com $14 \mathrm{ca}-$ choeiras catalogadas, inúmeras belezas naturais e nascentes, o parque tem ainda importantes campos rupestres, ecossistema riquíssimo em espécies endêmicas.

\section{REFERÊNCIAL TEÓRICO-ANALÍTICO - GOVERNANÇA E MEIO AMBIENTE}

Para Silva (2006), governança significa a melhora da capacidade de governar no nível local. A melhora se associa à gestão compartilhada de interesses e bens comuns, na qual os envolvidos passam de consumidores/beneficiários a definidores de políticas e de beneficiários a gestores. Esse padrão de interação entre governo e sociedade se expressa em diversos canais ou arenas, institucionalizados ou não. No 
caso dos espaços protegidos brasileiros, esses canais se materializam nos conselhos gestores. Não se trata de afastar o estado de seus papéis de mediação e coordenação, mas de fomentar a participação dos diversos setores sociais nas instâncias decisórias.

O PNUD define governança como o exercício de autoridade política, econômica e administrativa na condução dos assuntos públicos de um país, em todos os níveis. Inclui os mecanismos, processos e instituições por meio das quais os cidadãos e os grupos articulam os seus interesses, exercem os seus direitos legais, cumprem as suas obrigações e resolvem as suas diferenças. Este conceito reconhece que o poder existe dentro e fora da autoridade formal e das instituições governamentais. A governança tem como foco principal a construção de uma visão coletiva sobre a realidade local e o seu contexto, com base no envolvimento dos atores sociais, na corresponsabilidade e na efetivação de parcerias entre governo e sociedade. O fundamental é que estas novas formas de relacionamento rompam com a visão hierárquica e vertical de poder, criando controle social sobre as ações governamentais. Ocorre, assim, uma distribuição horizontal do poder, com base nos atores locais como sujeitos do processo, ampliando o sentido de governo local para uma governança local. Dessa forma, conselhos gestores, parcerias e planos de manejo de UCs podem ser laboratórios de governança ambiental, afetando - desejavelmente para melhor - a forma de gerir UCs e outras políticas ambientais (DRUMMOND; FRANCO; NINIS, 2006).
Instalar governança em uma UC não significa modificar a sua missão primordial de proteger a biodiversidade. Além dessa finalidade primordial, as UCs começam a ser vistas pelos formuladores de políticas públicas como instrumentos para apoiar a criação de novas formas de ocupação e renda para segmentos da população local. De fato, a melhoria da qualidade de vida das comunidades locais deve estar também dentro do horizonte dos objetivos da gestão via governança de UCs, embora tal melhoria dependa muito mais de numerosas outras ações e iniciativas públicas e privadas, que, em geral, guardam fraca relação com UCs e os seus formatos de gestão (DRUMMOND, 2006).

A gestão compartilhada de UCs deve manter a sua missão básica de proteção da biodiversidade, a missão original do conceito e das práticas das áreas naturais protegidas. Consolida-se, atualmente, na esfera ambiental, a necessidade da participação dos indivíduos direta ou indiretamente vinculados à gestão das UCs, com vistas a torná-los parceiros da proteção da biodiversidade. No entanto, a proteção da biodiversidade se torna cada vez mais um objetivo de políticas de estado e, por isso, não pode ficar ao sabor dos valores ou das necessidades imediatistas e particulares de indivíduos e comunidades, sejam ricos ou pobres.

A participação social, formal ou não, é entendida como o envolvimento dos atores interessados na gestão das UCs ${ }^{2}$ Esses atores devem opinar no encaminhamento das decisões, devem ter igualdade de acesso aos benefícios gerados e assumem o compromisso de conser-

2. A participação formal relaciona-se com instrumentos e iniciativas previstos e/ou apoiados por alguma lei ou política pública. A participação não-formal é aquela em que as ações se desenvolvem pelo esforço de agentes locais; não está formalmente prevista em lei ou em política pública. Ela é normalmente fruto de uma iniciativa original que, quando bem sucedida, pode criar as bases e demandas para a sua formalização e reprodução em outras áreas (LOUREIRO, 2003). 
var os recursos naturais. A participação se ampliou significativamente nos últimos anos no universo de diversas políticas públicas brasileiras, notadamente educação e saúde. No caso de políticas ambientais, é comum hoje haver exigências de participação social por parte dos agentes financiadores.

Segundo Drummond e Crespo (2000), o conceito de gestão participativa aplicado às UCs contempla o envolvimento das comunidades locais; o fortalecimento do sistema público responsável pela regulamentação e gerenciamento das UCs; a criação de novas engenharias institucionais que facilitem um processo decisório compartilhado e transparente; e o compromisso dos atores envolvidos com a continuidade dessa forma de gestão.

No plano normativo ou legal, a adoção do modelo participativo foi estimulada pela citada Lei 9.985/2000, pelo Decreto $4.340 / 2002$, que a regulamentou, e pelo Decreto 5.758/2006, que institui o Plano Nacional de Áreas Protegidas (MMA, 2006). Esses documentos consagram a inclusão da sociedade na gestão de áreas protegidas como condição básica para o alcance de seus objetivos. Apresentam uma série de diretrizes e estratégias de inclusão, como o respeito às práticas de manejo tradicionais, o reconhecimento de injustiças resultantes da criação de UCs e a repartição justa e equitativa dos benefícios advindos das UCs. O Programa de Trabalho sobre Áreas Protegidas da Convenção sobre Diversidade Biológica (CDB), aprovado em 2004, também adotou, como objetivo, intensificar e garantir a participação de comunidades indígenas e locais e de outros stakeholders na gestão das áreas protegidas (CDB, 2004).

A gestão participativa de áreas protegidas pode ser facilitada por uma etapa prévia de planejamento participativo. Isso estimularia o envolvimento das populações envolvidas, antes mesmo da criação dessas áreas, a partir da suposição de que somente haverá proteção da biodiversidade quando houver processos de gestão compartilhados (BRITO, 2003).

Essas formas de gestão podem ganhar nomes distintos, como parceria ou cogestão. No entanto, todas visam compartilhar as decisões gerenciais entre o órgão governamental responsável e as instituições e segmentos sociais interessadas nas UCs. Esses formatos podem ser consolidados também por meio de conselhos gestores, compostos inclusive por atores locais.

A governança de UCs se exerce por um processo contínuo de negociação sócio-política dos conflitos entre os atores. Esse modo de gerir implicaria mudanças necessárias no próprio Estado brasileiro, mudanças essas que ainda estão longe de acontecer. Os grandes interesses econômicos foram e continuam fortes e as comunidades locais raramente foram ou são atores na gestão dos interesses coletivos, apesar de quase duas décadas de vigência de princípios de descentralização de várias políticas governamentais. Não obstante, o envolvimento das populações locais rompe conceitualmente com a lógica "vertical" que norteou por muitos anos as políticas públicas brasileiras.

A nossa pesquisa privilegiou os integrantes dos conselhos gestores de UCs como fontes de informação. Portanto, cabe discutir brevemente esses conselhos. Ao reunirem atores governamentais e representantes da sociedade civil, eles são espaços de governança. Como dito acima, a legislação brasileira consagra os conselhos como o espaço oficial de participação da sociedade na gestão das UCs. O conselho deve ser o mais representativo possível das peculiaridades locais e o mais paritário possível, 
incluindo representantes dos órgãos públicos e da sociedade civil. Assim, devem ser contemplados, quando couber, os órgãos ambientais dos três níveis da Federação e órgãos de áreas afins, representantes da sociedade civil, membros da comunidade científica e de organizações nãogovernamentais ambientalistas, proprietários de imóveis, trabalhadores e setor privado, membros dos Comitês de Bacia Hidrográfica, da população residente e do entorno, inclusive trabalhadores rurais e povos indígenas (BRASIL, 2000). Os conselhos gestores, se devidamente conduzidos, auxiliam na negociação de conflitos locais, o que ajuda a diminuir as pressões antrópicas sobre o ambiente natural. Apesar das vantagens da formação desses colegiados, as UCs que têm conselhos formalizados e ativos são uma minoria no país (Drummond et al, 2006).

Assim, uma política moderna para as UCs deve contemplar o reconhecimento de que os atores locais são parte integrante da conservação dos recursos naturais, não podendo ser ignorados ou vistos como "inimigos" dos territórios protegidos. Pelo contrário, devem ser incorporados à conservação ambiental e à busca de alternativas socioeconômicas que não dilapidem os recursos naturais e os processos ecológicos em troca de formas precárias ou temporárias de subsistência.

\section{O ESTADO DA GESTÃO DOS PARQUES ESTADUAIS BAIANOS - UMA VISÃO QUAN- TITATIVA}

Esta seção descreve as principais constatações de nossa pesquisa a partir de uma análise quantitativa dos dados levantados. Veremos que as perguntas feitas e os dados coletados permitiram que a nossa análise identificasse diferenças significativas entre as condições e as perspectivas de gestão das três UCs estudadas. Adicionalmente, foi possível verificar que existe uma correlação significativa entre o grau e os momentos de participação ampliada, de um lado, e a qualidade da gestão de outro. As constatações de nossa pesquisa estão resumidas na Tabela 1 e no Gráfico 1 (anexados ao final do texto).

Seguem-se as principais constatações, ordenadas de acordo com os princípios de gestão definidos acima.

\section{- Legitimidade e participação de múltiplos atores.}

A análise desse princípio levou em conta as seguintes variáveis: atitudes pessoais do gestor da unidade (presteza das suas respostas); apoio $e$ participação comunitária (relação positiva entre comunidade e parque); características do conselho gestor (formação, representatividade, legitimidade, transparência e funcionamento); mitigação de conflitos; e processo de criação (consulta aos atores locais desde os estudos preliminares de criação do parque).

Com relação à primeira variável, os conselheiros do PESC e do PEMC atribuíram um valor $3,0^{3}$. Consideram que os gestores mantêm uma postura respeitosa com a comunidade, os visitantes e as organizações parceiras. Já os conselheiros de PESP atribuíram 4,0 a essa variáv-

\footnotetext{
3. Este valor e os que se seguem foram obtidos pelo somatório geral das alternativas assinaladas dentro de uma mesma variável, dividido pelo número de entrevistados. Cada variável tem cinco alternativas, pontuadas de 0 a 4,0 . Por exemplo, no PESC essa primeira variável obteve uma pontuação total de 48. Como foram entrevistados 16 conselheiros, a média foi 3,0.
} 
el, ponderando que o gestor está sempre atento e responde satisfatoriamente às solicitações.

A segunda variável mereceu 3,0 dos conselheiros do PESC. Eles declararam que existem mecanismos formais de participação da comunidade, ocorrendo também a participação informal e níveis medianos e altos de benefícios para os comunitários. Os membros do conselho do PEMC valoraram esta variável com 2,0, indicando uma cooperação medianamente cordial e de ajuda mútua entre o gestor do parque e a comunidade. Contudo, a comunidade não participa do planejamento nem da gestão da unidade, ainda que apoie o gestor; o aporte de benefícios para a comunidade é mediano. Já os conselheiros do PESP pontuaram esta variável com 4,0, informando que existem mecanismos formais de participação das comunidades e que o apoio delas é inquestionável, gerando muitos benefícios diretos para elas.

A terceira variável recebeu 3,0 dos conselheiros do PESC e do PEMC, indicando que os conselhos foram formados com base em uma relativa mobilização da comunidade, têm boa representatividade e tomam decisões de forma democrática. As informações produzidas são geralmente divulgadas e o conselho funciona permanentemente. A pontuação 4,0 do PESP se explica pelo fato de que ele foi criado com base em forte mobilização comunitária, tem forte representatividade e que as decisões são tomadas de forma democrática. Indica também que as informações são sempre divulgadas e que o conselho funciona permanentemente.

Com relação à quarta variável, novamente houve sintonia entre as respostas dos conselheiros dos PESC e do PEMC, que the deram a pontuação 2,0 . Isso indica que a participação das comunidades na gestão das UCs ajudou a minimizar alguns conflitos. Porém, continuam a existir ameaças à integridade dos parques. Os membros do conselho gestor do PESP pontuaram esta variável com 3,0, o que aponta para a minimização de conflitos. Existiam ameaças à integridade do parque, mas elas foram reduzidas ou eliminadas pela intervenção de atores locais.

A quinta variável deste princípio recebeu dos conselheiros do PESC a pontuação 0,0 , atestando que os atores locais só foram informados sobre a UC depois da sua criação. Os conselheiros do PEMC pontuaram esta variável com 2,0, pois os atores locais só foram consultados sobre a criação do parque quando da realização dos estudos técnicos preliminares. Contudo, houve consultas públicas. Já os conselheiros do PESP informaram que as comunidades participaram dos estudos técnicos preliminares, por meio de oficinas, consultas públicas e seminários. Em função disso, pontuaram esta variável com 4,0.

\section{- Igualdade e inclusividade}

As seguintes variáveis foram empregadas para analisar este princípio: existência e atualização do plano de manejo; compatibilidade do plano de manejo (face a outros instrumentos, como zoneamento, definição de responsabilidades institucionais etc.); nível de planejamento, ou a complexidade do processo de planejamento e a utilização de planos específicos (planos de investigação, de educação ambiental, uso público etc.); zoneamento, ou o ordenamento territorial da unidade e o reconhecimento dos seus limites.

Com relação à primeira variável, os conselheiros do PESC lhe deram 4,0, pois existe um plano de manejo elaborado de forma participativa, devidamente divulgado e implementado. Como o PEMC não tem plano de manejo, recebeu 0,0 . Os conselheiros do PESP informa- 
ram que o parque está elaborando o plano com a participação da comunidade local; atribuíram o valor 3,0 a esta variável.

A segunda variável também recebeu dos conselheiros do PESC o valor 4,0. Como ainda não têm planos de manejo aplicados, o PEMC e o PESP receberam 0,0 . Na terceira variável, as três UCs receberam 0,0 , pois carecem de instrumentos de planejamento específicos.

A quarta variável foi pontuada pelos conselheiros do PESC com 3,0, pois existe um zoneamento, mesmo que não reconhecido por todos. Por não terem planos de manejo e não disporem do Zoneamento Ecológico e Econômico (ZEE), o PEMC e o PESP não pontuaram nesta variável.

Quanto à quinta variável, os conselheiros do PESC e do PEMC lhes atribuíram 3,0, pois os limites das unidades estão definidos legalmente e são reconhecidos, mas embora não sejam respeitados pela comunidade. Já os conselheiros do PESP deram 4,0 a esta variável, pois os limites da unidade estão definidos legalmente e são reconhecidos e respeitados pelas comunidades.

\section{- Responsabilidade e transparência}

Foram consideradas as seguintes variáveis para analisar este princípio: capacidade do parque de gerar recursos próprios; capacidade de gestão, ou a ligação com fontes de financiamento e com parceiros que propiciem apoio financeiro e técnico; mecanismos de controle e auditoria; apoio institucional do órgão gestor; e intercâmbio, avaliado pela troca de informação, experiência e recursos entre as instituições pertinentes.

Quanto à primeira variável, os conselheiros dos três parques lhe deram o valor 2,0, pois nenhum parque tem mecanismo que lhe permita angariar recursos, apesar de os gestores terem iniciativa e dinamismo para captar tais recursos.

Os conselheiros do PESC e do PESP atribuíram 3,0 à segunda variável, pois o órgão gestor tem capacidade relativamente boa de se vincular a potenciais fontes de financiamento. Já os conselheiros do PEMC deram 1,0 a essa variável.

Com relação aos mecanismos de controle e auditoria, inexistem nos três parques; eles não pontuaram nesta variável. No tocante à quarta variável, os valores atribuídos pelos conselheiros do PESC e do PEMC foram iguais - 1,0 -, pois o órgão gestor não dá apoio suficiente aos parques, obrigando-os a gerenciar as suas próprias políticas e apoios. Os conselheiros do PESP deram 2,0 para esta variável, pois o órgão gestor se concentra principalmente em delinear políticas de conservação que geram certos apoios ao parque, sem, contudo, apontar para um sistema estadual integrado.

A última variável deste princípio mereceu 3,0 dos conselheiros do PESC, indicando que o intercâmbio e o aporte com outras instituições são permanentes. Os conselheiros do PEMC deram 2,0, sinalizando que existe um intercâmbio ad hoc e de periodicidade variada. Já os conselheiros do PESP atribuíram 1,0 para este quesito, indicando que o intercâmbio ocorre em função de necessidades imediatas.

\section{- Abertura à auditoria e equidade}

Para a análise deste princípio, consideramos as seguintes variáveis: regularização fundiária (indenização dos imóveis particulares e remanejo devido das famílias residentes); resolução de conflitos (relacionados com a posse de terras e com o uso dos recursos); clareza dos instrumentos legais; aplicação, acatamento dos instru- 
mentos legais; e conhecimentos tradicionais, em que se analisa o uso do chamado conhecimento tradicional e a sua possível contribuição para melhor gestão da unidade.

Com referência à primeira variável, os conselheiros do PESC lhe atribuíram 1,0, pois apenas $35 \%$ a $50 \%$ dos imóveis foram indenizados e das famílias foram realocadas. Os conselheiros do PEMC pontuaram esta variável com 0,0 , pois menos de $35 \%$ dos imóveis foram indenizados e das famílias realocadas. $\mathrm{Na}$ verdade, o processo ainda não foi desencadeado neste parque. Os conselheiros do PESP deram 4,0 a esta variável, atestando que mais de 90\% dos imóveis foram indenizados e as famílias foram devidamente realocadas.

A segunda variável mereceu a mesma pontuação, 3,0, dos conselheiros do PESC e do PESP, pois existem estratégias para a solução de conflitos relacionados com a posse e o uso das terras e dos recursos naturais. Algumas foram adotadas e parte dos conflitos foi solucionada. Os conselheiros do PEMC deram 1,0 para essa variável, informando que existem estratégias, porém elas não são adotadas e não solucionaram os conflitos.

A terceira variável mereceu 2,0 dos conselheiros do PESC, o que indica que existem lacunas e superposições no conjunto de instrumentos legais, prejudicando a gestão. Os conselheiros do PEMC deram o valor 1,0 a este quesito, indicando que existem conflitos entre os instrumentos legais. Os conselheiros do PESP atribuíram 4,0 a esta variável, evidenciando que o conjunto de instrumentos legais é claro e abrangente.

A quarta variável foi pontuada pelos conselheiros do PESC e do PEMC com 1,0, sinalizando que os instrumentos legais são obedecidos com muita dificuldade pelos usuários das unidades e que os seus técnicos se limitam a realizar controles e divulgações esporádicas. Os membros do conselho do PESP deram 3,0 a esta variável, atestando que os instrumentos legais são obedecidos pela maioria dos usuários com relativa facilidade e que os técnicos os divulgam satisfatoriamente.

A última variável deste princípio recebeu o valor 3,0 dos conselheiros do PESC e do PEMC, o que indica que os conhecimentos tradicionais das comunidades são conhecidos e aproveitados. Já os membros do colegiado do PESP pontuaram esta variável com 4,0, sinalizando que os saberes tradicionais são plenamente conhecidos, documentados e aproveitados.

\section{- Efetividade e eficiência}

As seguintes variáveis foram consideradas para a análise deste princípio: motivação do gestor; jurisdição, que leva em conta a clareza com que outras instituições exercem determinado poder, direito ou autoridade sobre a UC; alcance, entendido como a permanência do apoio externo à administração da UC; características do planejamento (existência e forma participativa de redação do plano de manejo); e investigação, avaliando a relação entre as investigações que realizadas e as necessidades de gestão do parque, assim como a disponibilidade de conhecimentos aplicáveis à gestão.

A primeira variável foi pontuada de maneira igual pelos conselheiros dos PESC e PEMC, que lhe atribuíram 3,0, indicando que a motivação dos gestores é forte, mesmo que existam conflitos com alguns setores das comunidades. Os conselheiros do PESP deram 4,0 a esta variável, o que sinaliza alta motivação do gestor.

A segunda variável recebeu dos mem- 
bros dos três conselhos a pontuação 3,0, indicando que existe clareza na jurisdição e nas regras institucionais. Porém, ocorrem certos conflitos de interesses entre determinadas instituições, mesmo que de fácil negociação.

A quarta variável recebeu o valor 2,0 do conselho do PESC, pois o plano de manejo foi elaborado por uma equipe multidisciplinar. Como o PEMC não tem plano de manejo, o valor dado a essa variável foi 0,0. Já o conselho do PESP concedeu 4,0 a essa variável, pois o plano de manejo está sendo elaborado por uma equipe multidisciplinar e pela comunidade.

A quinta variável deste princípio foi pontuada com o valor 3,0 pelos conselheiros do PESC e do PEMC, pois os estudos são realizados sem considerar a sua relevância para $\mathrm{O}$ manejo das unidades. Contudo, os resultados das pesquisas são conhecidos pela unidade. Para essa variável, os conselheiros do PESP deram um valor 4,0, porque as pesquisas e os estudos científicos são permanentes e os seus resultados estão disponíveis para a unidade.

Em suma, constatamos que o PESP e o PESC, que obtiveram 71 e 57 pontos, respectivamente, têm a gestão mais participativa. Ambos ficaram enquadrados na categoria de Gestão Medianamente Satisfatória (51 a 75\% do ótimo). O PEMC recebeu a menor pontuação, 37, ficando enquadrado na categoria de Gestão Pouco Satisfatória (36 a 50\% do ótimo).

\section{UMA VISÃO QUALITATIVA DO ESTADO DA GESTÃO}

Esta seção explora algumas dimensões analíticas qualitativas tratadas apenas limitadamente pela análise quantitativa. Algumas fontes de informação (atas de reuniões, relatórios de campo, anais de seminários e oficinas, manifestos e panfletos etc.) não foram citadas em nossas referências bibliográficas em função da ausência ou imprecisão de dados de identificação (autoria, data de publicação, origem etc.). Contudo, as informações nelas contidas foram devidamente checadas e validadas. Elas fundamentam a discussão de uma série de itens relevantes, enriquecendo muito as análises feitas na seção anterior.

\section{- A importância do gestor da unidade}

Foi constatada a importância de um forte grau de compromisso do gestor com o exercício das funções, mesmo na presença de circunstâncias adversas. As equipes técnicas são reduzidas, ou inexistentes, como no PEMC; vigilantes ou voluntários atuam como guarda-parques; faltam meios de comunicação básicos; até o envio de cartas é pago pelos gestores (SEMARH, 2006). As suas exigências fazem com que sejam mal compreendidos por alguns setores das comunidades. Contudo, eles são respeitados pela grande maioria dos atores, devido à presteza e à cordialidade. Ter raízes no município de Miguel Calmon e o fato de ter participado da criação do PESP talvez expliquem o bom conceito recebido pelo seu gestor.

\section{- Envolvimento e participação das comuni- dades e mitigação de conflitos}

A participação das comunidades locais na gestão dos parques estaduais ocorre com maior intensidade no PESP. O fato de ter havido uma mobilização e um comprometimento maiores na criação deve ter sido decisivo para isso. Outros pontos favoráveis foram o fato de a unidade proteger as fontes de recursos hídricos consumidos pelas comunidades vizinhas. Relatos indicam que, depois do fim do desmatamento, 
alguns rios renasceram. (SEMARH, 2006)

A mobilização das comunidades contra o plano de uma empresa de mineração de atuar no interior do parque comprovou o forte envolvimento das comunidades na gestão do PESP. Depois de uma concorrida reunião pública, na qual antigos moradores se manifestaram sobre a importância da unidade, os empresários repensaram o seu plano e o parque, a princípio, ficou livre desta ameaça.

Porém, a comunidade tem expectativa fraca quanto às vantagens criadas pelo parque para o turismo e o artesanato. Além disso, há moradores frustrados por não poderem visitar o PESP, já que a entrada passou a ser feita apenas pela portaria principal. Muitos veem o parque como um local de lazer reservado para turistas (UFBA, 2007).

A participação foi muito menor na criação do PEMC e nula no PESC, o que explica os conflitos ainda presentes na sua gestão. O PESC é desmatado sistematicamente, com a conivência de setores das comunidades. Nos seus dez anos de existência, a unidade conseguiu algum apoio popular, o que contribuiu para mitigar conflitos (FLORESTAVIVA, 2007). Contudo, a aceitação do parque por parte dos habitantes depende da resolução de outros conflitos.

O PEMC sofre também com conflitos antigos, ligados ao não-reconhecimento de seus limites. Isso provoca a ocupação informal de algumas de suas áreas. Apesar da mobilização da comunidade na época da sua criação, o envolvimento da população na sua gestão se limita a setores organizados e a líderes mais ativas. Comunidades do entorno ainda não incorporaram o PEMC ao seu modo de vida. Pelo contrário, continuam caçando e produzindo carvão vegetal (UEFS, 2006).
- Clareza e aplicação de instrumentos legais

Existem situações comuns às três unidades. As respectivas comunidades são unânimes quanto às reclamações contra regulamentos sobre o uso e a ocupação do espaço e dos recursos protegidos. É preciso uma maior divulgação deles. Outras situações conflituosas envolvem o caráter repressivo da fiscalização e a falta de esclarecimento sobre as práticas proibidas. Isso inibe as atividades agrícolas. Os conselheiros criticam a repressão às práticas agrícolas tradicionais, pois não há incentivos ou orientação para a adoção de práticas alternativas.

\section{- Os Conselhos Gestores}

A formação dos colegiados dos parques estaduais baianos seguiu uma mesma diretriz, foi bem aceita e não gerou conflitos graves. Os conselheiros elogiam a sua criação. Com relação à questão de direito à voz nos conselhos, as reuniões são abertas ao público e todos se manifestam livremente, independente de pertencerem ou não ao conselho. A liberdade de participação é reconhecida por todos, embora os setores menos articulados tenham dificuldades de lidar com as etapas da regularização de uma associação. Normalmente, as associações de pequenos produtores rurais são as que menos se fazem representar (SEMARH, 2006).

A falta de recursos financeiros é comum a esses conselhos e aos demais colegiados de UCs estaduais, o que pode comprometer a sua sustentabilidade. A inexistência de recursos financeiros atrelados a um Plano Operativo Anual (POA) ou a um orçamento próprio, dificulta o seu funcionamento, impedindo reuniões em local próprio e a cobertura de despesas de deslocamento, alimentação e hospedagem. Isso deixa o colegiado na dependência de órgãos 
públicos ou de outras entidades, que às vezes se movem por seus interesses particulares. Isso pode ameaçar a independência dos conselheiros (SEMARH, 2006).

Constatou-se que a participação social é ainda incipiente, sujeita a toda uma cultura que inibe o exercício de práticas democráticas, especialmente pela população menos escolarizada, fato comum em diversas outras instâncias participativas. Contudo, uma grande parcela dos conselheiros tem uma visão positiva sobre os conselhos, apoia as iniciativas dos gestores das unidades e é otimista com relação ao futuro.

\section{- Processo de criação das unidades}

O processo de criação do PESP foi o mais participativo dentre os três parques estaduais. Começou em 1996, com um trabalho da Prefeitura de Miguel Calmon e da Associação de Produtores Rurais junto aos garimpeiros e produtores de gado, para sensibilizá-los a preservar os recursos naturais. A criação do parque ocorreu depois de reuniões com as comunidades (UFBA, 2007). A criação da UC foi apoiada por recursos de compensação ambiental. As comunidades não participaram do processo, o que levou a sérios conflitos fundiários. Parcela significativa dos atores associa a UC ao aumento da fiscalização contra práticas antigas (agricultura, pesca, caça etc.), o que reforça conflitos. O fato de a população se sentir excluída das discussões anteriores à criação da UC contribuiu para acirrar as antipatias dos prejudicados. A criação do PEMC foi menos traumática, porém igualmente pouco participativa. Houve reuniões com a comunidade, mas há informações de que a maior parte da população não estava ciente da criação da UC (CAJAZEIRA, 1998).
Parece que, ao criar essas unidades sem debates com as populações locais, o estado optou por um caminho menos traumático. Preferiu evitar confrontos no primeiro momento. Isso apenas adiou os conflitos e, ao que parece, contribuiu para o seu aprofundamento. A maior parte da população foi surpreendida pelas medidas e até hoje não compreende o motivo de criação das UCs (SEMARH, 2006).

\section{- Parcerias e articulações}

Uma das atribuições do conselho gestor de uma UC é "avaliar o orçamento da Unidade e o relatório financeiro anual elaborado pelo órgão executor" (SNUC, 2000). Contudo, os parques estaduais não são unidades orçamentárias autônomas, pois se subordinam aos procedimentos e controles financeiros da SEMABA. Os gestores não têm competência para firmar convênios, parcerias ou qualquer instrumento de cooperação técnica ou financeira. No entanto, o desempenho da gestão de uma UC está intimamente relacionado à capacidade de coordenar esforços de identificar e formalizar parcerias (CAMARGO, 2003). No caso dos parques estaduais baianos, esta tarefa é impossível, pois a proibição de iniciativas locais e a ausência de dotação orçamentária própria limitam a construção de parcerias. Exemplos de parcerias bem sucedidas com o órgão gestor ocorreram no PESC, com a elaboração do plano de manejo e as campanhas de fiscalização. Essas cooperações foram firmadas com a Unidade de Coordenação Estadual (UCE) do Projeto Corredores Ecológicos. Este projeto nasceu com apoio o Programa Piloto para a Proteção das Florestas Tropicais do Brasil - PP-G7 (MMA/ SEMARH, 2004).

Outra parceria de sucesso foi firmada com o Instituto de Estudos Socioambientais do 
Sul da Bahia (IESB), ONG que executa projetos ambientais no entorno do PESC. O Instituto Floresta Viva (IFV), outra ONG, atua junto aos posseiros e produtores rurais locais. O IFV e o IESB desenvolvem também, em parceria com o órgão gestor, o programa de reflorestamento de áreas de preservação permanente, empregando mudas de árvores nativas. Esse projeto possibilitou a capacitação de viveiristas (SEMARH, 2006).

O PEMC ainda não conseguiu um parceiro de peso. A principal parceria foi com a Universidade Estadual de Feira de Santana (UEFS), que finalizou os estudos de redefinição da poligonal da unidade. Existe um parceiro potencial, a Companhia de Pesquisa de Recursos Minerais (CPRM), que se interessa por apoiar um projeto de educação ambiental para o entorno da unidade.

O PESP tem na prefeitura local o seu maior aliado e uma das maiores razões do seu sucesso. Todas as ações passadas e presentes tiveram o seu apoio, principalmente financeiro. Como exemplo, citamos a delimitação e as obras da prefeitura de aceiramento e cercamento do parque (UFBA, 2007). Atualmente, o parque tem seis guarda-parques e um administrador, escolhidos por eleição nas comunidades do entorno, numa iniciativa conjunta da SEMA, da Prefeitura e da Associação Protetora da Serra, uma ONG. O parque conta ainda com voluntários e guias turísticos (aprendizes não-remunerados ) (UFBA, 2007).

\section{- Regularização fundiária}

A regularização fundiária foi menos problemática no PESP. Apesar de estar em terras devolutas, existiam lá 14 garimpeiros que, por não terem benfeitorias, não foram indenizados. Segundo estudo da UFBA (2007), a prefeitura de Miguel Calmon indenizou os garimpeiros. Cada um recebeu a quantia de $\mathrm{R} \$ 1.500,00 \mathrm{e}$, em alguns casos, nova moradia ou terras em outras áreas do município. O problema maior ocorreu com os criadores de gado. Após negociações, o gado foi retirado e o problema foi resolvido. Quando da definição da poligonal da unidade, houve a preocupação de não incluir áreas particulares. Para consolidar a posse, a prefeitura cercou todos os acessos. Atualmente, existe apenas uma propriedade particular no interior do parque. Porém, como a área é fortemente antropizada, ela pode vir a ser excluída da unidade (UFBA, 2007).

O PEMC ainda não iniciou a sua regularização fundiária, nem existem perspectivas disso. Isso vem tendo sérias consequências, pois os seus limites não são respeitados pelas comunidades. Existe o agravante da presença no entorno de vários assentamentos de reforma agrária, que podem avançar em direção à unidade (UEFS, 2006).

$\mathrm{O}$ processo de regularização fundiária mais traumatizante ocorre PESC. Cerca de 120 famílias de posseiros e pequenos proprietários vivem no interior do parque, esperando indenizações. Isso acarreta impactos ambientais e sociais. Do ponto de vista ambiental, essas famílias pobres dependem dos recursos naturais para sobreviver, praticando a caça, vendendo madeira e fazendo agricultura de corte e queima (SEMARH, 2006). Do ponto de vista social, a morosidade do processo amplia os problemas, pois o crescimento da população leva ao sub-parcelamento das posses. O problema se agrava pelo fato de essas famílias não poderem ampliar as áreas de roçado, o que limita as suas condições de sobrevivência. Elas procuram outras fontes de renda, aumentando a pressão sobre os ecossistemas (FLORESTAVIVA, 2007). 
A grande maioria das famílias de agricultores familiares declara estar disposta a sair da área do parque se for paga uma indenização justa. A desapropriação de apenas parcelas de suas posses as transformaria em minifúndios, provavelmente pequenos demais para garantir a sua sobrevivência. Até junho de 2007, 35\% das propriedades particulares inseridas nos limites do parque tinham sido indenizadas. Havia previsão de que até dezembro de 2007 seriam indenizadas mais 30 famílias, elevando a área indenizada a $42,18 \%$ da área total a ser desapropriada (SEMARH, 2006).

\section{- Conhecimentos tradicionais e geração de renda}

Há poucos incentivos a projetos desenvolvidos pelas comunidades nas três UCs estudadas, se bem que esse tipo de apoio requer a participação de outras entidades além dos parques estaduais. No PESP existe uma parceria entre a Secretaria de Agricultura e Meio Ambiente do Município de Miguel Calmon e a comunidade de Morcego, situada no entorno da unidade, para estimular a produção de artefatos de fibra de sisal, ouricuri, babaçu e argila (UFBA, 2007). Existem, na região do PESC, formações de palmeiras de piaçava e coqueiros, cujas fibras e folhas podem ser feitas peças de artesanato e coberturas de construções. As raízes de algumas lianas (como o cipó-verdadeiro) também podem ser utilizadas para artesanato (MOREAU, 2003). Essas potencialidades devem ser incentivadas por SEBRAE, EMATER, EMBRAPA, bancos, sindicatos, cooperativas etc., com apoio dos gestores das unidades, de forma a criar outras fontes de renda para as comunidades.

\section{- Pesquisas e visitação}

Os parques estaduais baianos, apesar de toda a sua riqueza biológica, foram até agora pouco explorados para fins de pesquisa cientifica. $\mathrm{O}$ PESC foi objeto de alguns estudos. Nenhum trabalho que mereça destaque foi desenvolvido no PEMC e no PESP. Alguns levantamentos de fauna e flora e estudos pontuais foram realizados por pesquisadores autônomos ou vinculados a instituições de pesquisas e universidades, a grande maioria do próprio Estado, com objetivo puramente acadêmico, desvinculados da gestão do parque.

Da mesma forma, faltam estudos sistemáticos sobre a visitação das unidades. Quando existem, os dados são desatualizados e mal organizados. Não formam séries históricas confiáveis; o perfil dos visitantes é desconhecido; pouco se sabe sobre o nível de satisfação dos usuários e sobre as suas demandas; nunca se estudou a capacidade de carga de visitação. A frequência média anual de visitas no PESP é estimada em 4.200. No PESC a média anual é de apenas 600 visitantes e, para o PEMC, não existe uma cifra confiável. Porém, como existe uma associação que leva visitantes até o parque, é provável que um número significativo de pessoas não-registradas frequente o PEMC. Parte desses visitantes vem de fora do estado e até do exterior. Contribuem também para a fraca visitação a insuficiência de recursos humanos (guias, guarda-parques, etc.) e a falta de instalações adequadas (lanchonetes, áreas de recepção, banheiros, etc.), de sinalização e de trilhas adequadas.

\section{CONSIDERAÇÕES FINAIS}

A pesquisa constatou que existem diferenças significativas entre os três parques estad- 
uais baianos. PESC e PESP têm uma gestão mais participativa, enquadrada em "gestão medianamente satisfatória". Três variáveis "puxaram para baixo" a cotação da gestão PESC: a nãoparticipação das comunidades locais na sua criação; depredações (desmatamento e caça ilegais); e a regularização fundiária inconclusa. O PESP ficou no limiar entre as faixas de "gestão medianamente satisfatória" e "gestão satisfatória". Poderia ter entrado na classificação mais alta se o seu plano de manejo fosse aplicado. O PEMC alcançou a menor pontuação, ficando enquadrado numa "gestão pouco satisfatória". Ficou bem próximo da faixa de "gestão insatisfatória", fato atribuível principalmente à falta de poligonal definida, de regularização fundiária e de plano de manejo.

Falta muito para efetivar uma gestão adequada nas UCs no Brasil. Já se passaram mais de 75 anos desde a criação da primeira área federal legalmente protegida em nosso país, o Parque Nacional de Itatiaia (1937). Em termos gerais, os avanços foram desiguais e às vezes pouco significativos, tanto em unidades antigas quanto nas novas. Os casos de sucesso ainda são poucos, e mesmo excepcionais. Muitos fatores contribuem para isso. Um deles é a incipiente participação comunitária nos processos de criação, implantação e gestão e a consequente ausência de instâncias de governança local. A atuação dos indivíduos e grupos locais muitas vezes promove mudanças na cultura de suas organizações e da comunidade, afetando a maneira de gerir as unidades.

Sem destoar do contexto nacional, as UCs do estado da Bahia - inclusive os seus parques - deixaram à margem, na sua grande maioria, os segmentos sociais diretamente afetados pela sua criação e gerência. Eles sofrem as consequências de uma estrutura política his- toricamente centralizada, verticalizada e pouco participativa. Esse quadro fica patente nas agressões ambientais a essas unidades, como desmatamentos, queimadas, extração clandestina de madeiras e de espécimes da sua fauna e flora, conflitos fundiários. Não surpreende que o PESP, que envolveu as comunidades locais desde a sua criação, tenha alcançado o melhor desempenho no presente estudo. As outras duas unidades, que se abriram à participação apenas mais recentemente, sofrem rejeição maior e vivenciam conflitos mais graves.

Existe um consenso de que só o avanço da democracia levará à sustentabilidade de políticas ambientais, por meio da criação de espaços de negociação e do fortalecimento dos conselhos gestores e das audiências públicas. Os caminhos de construção da governança ambiental apontam para uma gestão que se baseie na ampla participação da comunidade nas tomadas de decisão. Assim, a inclusão dos atores sociais na gestão de áreas protegidas depende do funcionamento de espaços institucionais, mas, também, e principalmente, da capacitação da sociedade para participar. O conselho gestor é o principal espaço instituído de governança ampliada nas UCs. Se funcionar devidamente, mitigará conflitos, reduzirá pressões antrópicas sobre o ambiente e poderá contribuir para a adoção de atividades produtivas sustentáveis. Isso melhorará o padrão de vida das comunidades, que passarão a entender a importância da implantação das áreas protegidas e a aceitar as inevitáveis restrições que elas geram nas suas vidas. Contudo, ainda é necessário definir com clareza mecanismos e instrumentos que promovam a participação social nesses colegiados. Duas delas seriam a alocação de recursos, para dotar os conselhos de autonomia financeira, e a capacitação de seus membros. 
É fato também que temos um razoável conjunto de leis e regulamentos - externos aos que definem as UCs e as áreas protegidas - que disciplinam a exploração dos recursos naturais - água, madeira, flora, fauna, minérios. Porém, a prática demonstra que ainda são limitados os seus efeitos, principalmente pela falta de aparelhamento dos órgãos responsáveis e pela ausência de políticas que propiciem a inserção de atores locais na gestão dessas políticas.

O reduzido número de parcerias e cogestões de UCs precisa ser revertido, pois elas geram recursos humanos e financeiros. Da mesma forma, os administradores das UCs devem se aproximar mais da comunidade científica, pois ela pode ser mais uma aliada, realizando pesquisas que informem os programas de manejo e obtendo recursos humanos e financeiros. Os trabalhadores voluntários formam um terceiro grupo a ser atraído para trabalhar em favor das UCs.

A não-participação de atores locais no planejamento e gestão das UCs dificulta o alcance de sua missão principal - a proteção da biodiversidade. É preciso alargar e melhorar a articulação entre o Poder Público (nas diferentes esferas) e a comunidade, buscando o diálogo e o equilíbrio das atividades econômicas, sociais e ambientais, traçando estratégias para conciliar os interesses dos que tradicionalmente usam as áreas dos parques como fonte de sobrevivência e as restrições impostas por UCs de proteção integral. O próprio monitoramento científico da biodiversidade precisa se sistematizar para se ter a medida em que as UCs estão cumprindo a sua finalidade principal.

Por fim, a participação, em termos gerais, é um direito e uma necessidade social contemporânea; ela ajuda a desenvolver a consciência crítica e a ganhar poder e capacidade de autodeterminação. A participação leva a população a se apropriar do desenvolvimento. É algo que se aprende e aperfeiçoa. Ela pode ser estimulada e organizada, sem que isso signifique necessariamente manipulação.

Cabe lembrar dois pontos cruciais: (i) os potenciais propriamente desenvolvimentistas das UCs são, quase sempre, muito limitados; e (ii) esses potenciais nunca superam os das políticas públicas básicas, como educação, saúde, saneamento, segurança, transporte, justiça, previdência social etc. Exagerar o potencial desenvolvimentista de UCs não as ajuda a cumprir a sua finalidade principal - a proteção da biodiversidade, ao mesmo tempo complexa e pontual. Além disso, essa expectativa excessiva desvia a atenção dos analistas - e talvez dos cidadãos - sobre a implantação dessas outras políticas públicas, que têm capacidade muito maior de melhorar a qualidade de vida do conjunto dos cidadãos brasileiros, em geral, e dos subconjuntos de cidadãos que residem nas vizinhanças das UCs, em especial.

\section{REFERÊNCIAS BIBLIOGRÁFICAS}

ANGELO, J. G. M. A conservação da biodiversidade através da gestão de unidades de conservação do estado da Bahia - atualidades, potencialidades e desafios. Bahia Análise \&o Dados. Salvador, v. 13, n. 3, p. 641-652. 2003.

BRASIL, Lei 9.985, de 18 de Julho de 2000. Institui o Sistema Nacional de Unidades de Conservação da Natureza - SNUC. Brasília

BRITO, D. M. C. A Construção do Espaço Público na Gestão Ambiental de Unidades de 
Conservação: O caso da APA do Rio Curiaú/ AP. Dissertação (Mestrado em Desenvolvimento Sustentável). Centro de Desenvolvimento Sustentável, Universidade de Brasília. Brasília, 2003.

CAJAZEIRA, H. S. Proposta para elaboração do zoneamento do Parque Estadual de Morro do Chapéu - Bahia. Salvador,1998. Monografia. Instituto Estadual de Florestas de Minas Gerais. Universidade Estadual de Minas Gerais. Salvador, 1998.

CAMARGO, A. Meio Ambiente e Governança. In: TRIGUEIRO, André. Meio Ambiente no Século 21: 21 especialistas falam na gestão ambiental nas suas áreas de conbecimento. Rio de Janeiro, Sextante, 2003.

CARVALHO, L. M. F. de. Gestão de Áreas de Proteção Ambiental no Estado da Babia: Análise de um Modelo em Construção. Brasília, 2004. Dissertação (Mestrado em Desenvolvimento Sustentável). Centro de Desenvolvimento Sustentável, Universidade de Brasília. Brasília, 2004.

CDB, 1992. 2004. Programa de Trabalho sobre Áreas Protegidas. Texto disponível em < http:// www.mma.gov.br >. Acessado em 25 out.2006.

CIFUENTES, A. M.; IZURIETA, A.; DE FARIA, H. H. Medición de la efectividad del manejo de areas protegidas. Turrialba, CC.R.WWF: IUCN, GTZ, 2000.

DRUMMOND, J. A.; CRESPO, S. O Parque Nacional da Tijuca: contribuição para a gestão compartilhada de uma unidade de conservação urbana. Série Comunicações do ISER, n ${ }^{\circ} 54$, ano 19. Rio de Janeiro, Editora ISER, 2000.

DRUMMOND, J. A.; FRANCO, J. L. A.; NINIS, A. B. 2006 O Estado das Áreas Protegidas do Brasil - 2005. Brasília, Centro de Desenvolvimento Sustentável. Disponível em: <http://www.unbcds.pro.br/pub/index. cfm?CODE $=01 \& \mathrm{COD}=27 \& \mathrm{X}=219>$. Acessado em 25 out.2006.

DRUMMOND, J. A.; FRANCO, J. L. A; NINIS, A. B. Novas dimensões da governança de unidades de conservação federais brasileiras: conselhos gestores, parcerias e planos de manejo. In: Encontro Governança Ambiental no Brasil: contexto, realidade, rumos. Olinda, Instituto de Pesquisas Sociais da Fundação Joaquim Nabuco, 2006.

FARIA, H. H. de. Aplicação do Emap e rotinas estatísticas complementares na avaliação da eficácia de gestão de unidades de conservação do estado de São Paulo. Revista Ciências do Ambiente. v. 2, n. 2, p. 185-219, 2006.

FLORESTAVIVA. Instituto Floresta Viva. Implementação e criação de unidades de conservação no Corredor Central da Mata Atlântica com ênfase no Sul e Baixo Sul da Bahia. Relatório parcial. I e II trimestres, 2007.

GRAHAM, J.; AMOS, B.; PLUMPTRE, T. Governance principles for protected areas in the 21st century. Durban: UICN, 2003.

IPEMA. Instituto de Pesquisas da Mata Atlântica. Avaliação do manejo de unidades de conservação do Corredor Central da Mata Atlântica: princípios, critérios e indicadores. Vitória, ES:2003. 
LEITE, J. F. As Unidades de Conservação Estaduais: uma análise da realidade goiana. 2004. Dissertação (Mestrado em Desenvolvimento Sustentável). Centro de Desenvolvimento Sustentável, Universidade de Brasília. Brasília.

LOUREIRO, C. F. B. Gestão ambiental participativa em unidades de conservação. In: Governo do Estado da Bahia. Cidadania e Meio Ambiente. Série Construindo os Recursos do Amanhã. Salvador, Centro de Recursos Ambientais - CRA; Núcleo de Estudos Avançados do Meio Ambiente - NEAMA. Volume 1, 2003.

LOUREIRO, C. F. B.; AZAZIEL, M.; FRANÇA, N. Educação ambiental e conselho em unidades de conservação: aspectos técnicos e metodológicos. Rio de Janeiro, Ibase; Instituto TerrAzul; Parque Nacional da Tijuca, 2007.

MMA - Ministério do Meio Ambiente, dos Recursos Hídricos da Amazônia Legal. Política Ambiental Integrada para o Desenvolvimento Sustentável. Relatório de Gestão: 2003 - 2006. Brasília, 2006.

MMA - Ministério do Meio Ambiente, dos Recursos Hídricos da Amazônia Legal. Programa Nacional da Diversidade Biológica. Projeto de Conservação e Utilização Sustentável da Diversidade Biológica Brasileira. Áreas prioritárias para a conservação, utilização sustentável e repartição de benefícios da biodiversidade brasileira. Brasília, PRONABIO / PROBIO, 2001.

MMA - Ministério do Meio Ambiente, dos Recursos Hídricos da Amazônia Legal. Secretaria de Biodiversidade e Florestas. Diretrizes para a visitação em unidades de conservação. Série
Áreas Protegidas do Brasil, 3. Brasília, $2006 a$.

MMA - Ministério do Meio Ambiente, dos Recursos Hídricos da Amazônia Legal. Secretaria de Biodiversidade e Florestas. Plano Nacional Áreas Protegidas. Brasília, 2006b.

MMA - Ministério do Meio Ambiente, dos Recursos Hídricos da Amazônia Legal. SEMARH; Secretaria de Meio Ambiente e Recursos Hídricos do Estado da Bahia. Plano de Manejo do Parque Estadual da Serra do Conduru. Salvador, Bahia, 2004.

MOREAU, M. S. Planejamento do uso da terra na zona tampão do Parque Estadual da Serra do Conduru no Litoral Sul da Bahia. Viçosa, 2003. Tese de Doutorado. Universidade Federal de Viçosa. Viçosa, Minas Gerais, 2003.

SEAGRI. Secretaria de Agricultura, Irrigação e Reforma Agrária do Estado da Bahia. Departamento de Desenvolvimento Florestal. Projeto de criação de unidades de criação: Parque Estadual das Sete Passagens. Salvador, Bahia,1997.

SEMARH. Secretaria de Meio Ambiente e Recursos Hídricos do Estado da Bahia. Superintendência de Biodiversidade, Florestas e Unidade de Conservação. Relatório de Atividades. Salvador, Bahia, 2006.

SILVA, D. J. Desafios sociais da gestão de bacias hidrográficas: uma introdução ao conceito de governança da água. In: Congréss de L'acfas. Université Mcgill, 74. Montreal: 2006.

UEFS. Universidade Estadual de Feira de Santana. Projeto de Redefinição da Poligonal do Parque Estadual de Morro do Chapéu. Salvador, 
Bahia, 2006.

UFBA. Universidade Federal da Bahia. Plano de Manejo do Parque Estadual das Sete Passagens.

Salvador, Bahia, 2007.

UFBA. Universidade Federal da Bahia. Plano de Manejo do Parque Estadual das Sete Passagens. Salvador, Bahia, 2007.

ANEXO

Tabela 1

Pontuação geral alcançadas a partir das informações produzidas sobre a governança dos três parques estaduais baianos

\begin{tabular}{|l|c|c|c|}
\hline Princípios & Serra Conduru & Morro Chapéu & Sete Passagens \\
\hline 1. legitimidade e participação de múltiplos & $3,3,3,2,0=11$ & $3,2,3,2,2=12$ & $4,4,4,3,4=19$ \\
atores & $4,4,0,3,3=14$ & $0,0,0,0,3=3$ & $3,0,0,0,4=7$ \\
2. igualdade e inclusividade & $2,3,0,1,3=8$ & $2,1,0,1,2=6$ & $2,3,0,2,1=8$ \\
3. responsabilidade e transparência & $1,3,2,1,3=10$ & $0,1,1,1,3=6$ & $4,3,4,3,4=18$ \\
4. abertura à auditoria e à equidade & $3,3,3,2,3=14$ & $3,3,1,0,3=10$ & $4,3,4,4,4=19$ \\
5. efetividade e eficiência & 57 & 37 & 71 \\
\hline Notas & 5 & & \\
\hline
\end{tabular}

Gráfico 1 - Resultado final - pontuação acumulada da eficácia da gestão dos três parques estaduais da Bahia

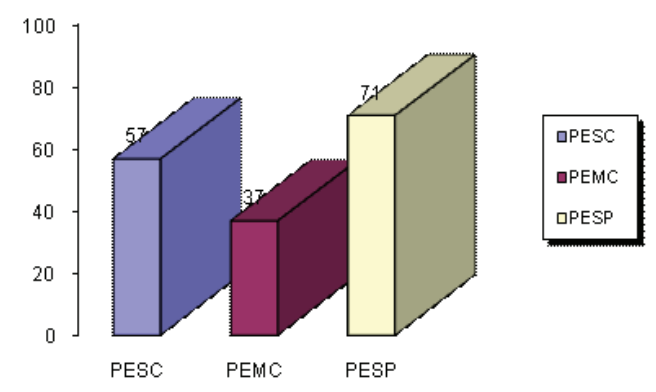

